\title{
26. A New Molecular Clock of Mitochondrial DNA and the Evolution of Hominoids
}

\author{
By Masami Hasegawa, *) Taka-aki YANo,**) \\ and Hirohisa KIsHINo*) \\ (Communicated by Motoo Kimura, M. J. A., April 12, 1984)
}

The approximate constancy of the rate of change is one feature of molecular evolution. It is consistent with the neutral theory ${ }^{1)}$ and serves as a clock to date a divergence time of organisms. ${ }^{2), 3)}$ Since Sarich and Wilson, ${ }^{4)}$ many researchers have estimated the divergence time between man and the African apes using the molecular clock (for review, see ref.5). In spite of diverse materials and methods used, their results are similar and show a recent divergence of 4-6 million years (Myr) ago. This dating does not contradict with any fossil evidence, if Ramapithecus is placed on orangutan line.5),6) The molecular clock, however, is not yet free of any contradiction with hominoid fossil records. The clock estimate of the divergence time between orangutan and man is between $8 \mathrm{Myr}^{4)}$ and $10 \pm 3 \mathrm{Myr}$ ago, ${ }^{5)}$ though recent finding indicates that orangutan and man diverged at a minimum of $13 \mathrm{Myr}$, probably more than 14.5 Myr. ${ }^{7)}$ The clock dated the split of gibbons from man between $10 \mathrm{Myr}^{4)}$ to $12 \pm 3 \mathrm{Myr}$ ago.5) But the fossil evidence indicates that Epipliopithecus and Micropithecus are 16 and $20 \mathrm{Myr}$ old, respectively, and are ancestors of gibbons. ${ }^{8)}$ Since the previous estimates of genetic distances are indirect, we performed a direct comparison among mitochondrial DNA (mtDNA) sequences.

Our data are the L-strand mtDNA sequences of 896 nucleotides from five species of hominoids, ${ }^{9)}$ from bovine, ${ }^{10)}$ and from mouse. ${ }^{11}$ ) This segment contains genes for three tRNAs and parts of two proteins. In animal mtDNA, it is known that transition predominates over transversion, ${ }^{9}{ }^{2}$ and that the substitution at the third codon position is much more frequent than other nucleotide positions. The numbers of transition and transversion type differences between species are listed in Table I separately for the third codon positions (class 1 sites) and for the rest (class 2 sites).

Table I indicates that mouse (splitting date: $t_{1}$ Myr ago), bovine

*) The Institute of Statistical Mathematics, 4-6-7, Minami-Azabu, Minato$\mathrm{ku}$, Tokyo 106 .

**) College of Arts and Sciences, Showa University, Fuji-Yoshida, Yamanashi 403. 
Table I. Number of transition (upper right half) and transversion (lower left half) type nucleotide differences among mammalian mtDNAs

\begin{tabular}{|c|c|c|c|c|c|c|c|c|c|}
\hline$i$ & & $\begin{array}{l}1 \\
\text { Mouse }\end{array}$ & $\stackrel{2}{\text { Bovine }}$ & $\stackrel{3}{\text { Gibbon }}$ & $\begin{array}{l}4 \\
\text { Orang }\end{array}$ & $\stackrel{5}{\text { Gorilla }}$ & $\begin{array}{l}6 \\
\text { Chimp }\end{array}$ & Man & $S^{(i)}$ \\
\hline 1 & Mouse & & $68(39)$ & $81(53)$ & $81(48)$ & $87(46)$ & $79(50)$ & $79(51)$ & $0.119(0.206)$ \\
\hline 2 & Bovine & $91(82)$ & & $80(42)$ & $81(44)$ & $93(52)$ & $85(61)$ & $86(57)$ & $0.128(0.221)$ \\
\hline 3 & Gibbon & $83(83)$ & $69(71)$ & & $57(59)$ & $65(59)$ & $61(64)$ & $59(58)$ & $0.091(0.259)$ \\
\hline 4 & Orang & $90(85)$ & $65(65)$ & $18(34)$ & & $64(52)$ & $59(60)$ & $55(53)$ & $0.089(0.237)$ \\
\hline 5 & Gorrila & $85(77)$ & $72(67)$ & $19(26)$ & $15(18)$ & & $28(58)$ & $32(52)$ & $0.045(0.237)$ \\
\hline \multirow[t]{3}{*}{6} & Chimp & $86(79)$ & $71(67)$ & $18(26)$ & $16(18)$ & $5(4)$ & & $24(50)$ & $0.036(0.216)$ \\
\hline & Man & $89(77)$ & $70(67)$ & $19(26)$ & $15(20)$ & $4(4)$ & $3(2)$ & & \\
\hline & $v^{(i)}$ & $\begin{array}{c}0.131 \\
(0.347)\end{array}$ & $\begin{array}{c}0.104 \\
(0.291)\end{array}$ & $\begin{array}{c}0.028 \\
(0.121)\end{array}$ & $\begin{array}{c}0.023 \\
(0.080)\end{array}$ & $\begin{array}{c}0.007 \\
(0.017)\end{array}$ & $\begin{array}{c}0.005 \\
(0.009)\end{array}$ & & \\
\hline
\end{tabular}

Number in parenthesis is for the third codon positions of protein-coding regions (class 1 sites; 232 nucleotides) and the one preceding it is for the rest (class 2 sites; 664 nucleotides).

$\left(t_{2}\right)$, gibbon $\left(t_{3}\right)$, orangutan $\left(t_{4}\right)$, gorilla $\left(t_{5}\right)$, and chimpanzee $\left(t_{6}\right)$ separated from the line leading to man in this order. In calibrating the clock, we take $t_{2}=90 \mathrm{Myr} .^{2), 3)}$ We assume that $f_{k}$ fraction of class $k$ $(k=1$ or 2 ) sites are variable and the remaining sites are invariable. The base composition of animal mtDNA is highly biased (particularly, $G$ is scarce in L-strand), and asymmetry of substitution frequency is in accord with the bias in base composition $(A \rightarrow G$ frequency is much lower than $G \rightarrow A$ ). ${ }^{12)}$ Therefore, we assume that a change at a variable site of class $k$ is a Markov process which is independent of others, and that a base $i(T, C, A$, or $G)$ is replaced by another base $j$ in an infinitesimally short interval of time, $d t$, with a probability of $P_{i j}^{k}(d t)$ as follows:

$$
P_{i j}^{k}(d t)=\pi_{j}^{k} u_{i j}^{k} d t
$$

$u_{i j}^{k}$ 's are $\alpha_{k}$ for transitions and $\beta_{k}$ for transversions. And $\pi_{T}^{k}, \pi_{C}^{k}, \pi_{A}^{k}$ and $\pi_{G}^{k}$ are compositions of $T, C, A$, and $G$. They are $0.169,0.429$, 0.364 , and 0.038 for class 1 sites, and $0.297,0.267,0.310$, and 0.126 for class 2 sites. Expectations of transversion and transition type differences for class $k$ sites, denoted by $V_{k}(t)$ and $S_{k}(t)$, between two sequences separated $t$ Myr ago are given by the following formulae,

( 2 ) $\overline{V_{k}\left(t ; f_{k}, \beta_{k}\right)}=2 f_{k} \pi_{Y}^{k} \pi_{R}^{k}\left\{1-\exp \left(-2 \beta_{k} t\right)\right\}$,

(3) $\quad S_{k}\left(t ; f_{k}, \alpha_{k}, \beta_{k}\right)=2 f_{k}\left[\left(\pi_{T}^{k} \pi_{C}^{k}+\pi_{A}^{k} \pi_{G}^{k}\right)\right.$

$$
\begin{gathered}
+\left(\pi_{T}^{k} \pi_{C}^{k} \pi_{R}^{k} / \pi_{Y}^{k}+\pi_{A}^{k} \pi_{G}^{k} \pi_{Y}^{k} / \pi_{R}^{k}\right) \exp \left(-2 \beta_{k} t\right) \\
-\left(\pi_{T}^{k} \pi_{C}^{k} / \pi_{Y}^{k}\right) \exp \left\{-2 t\left(\alpha_{k} \pi_{Y}^{k}+\beta_{k} \pi_{R}^{k}\right)\right\} \\
\left.\quad\left(\pi_{A}^{k} \pi_{G}^{k} / \pi_{R}^{k}\right) \exp \left\{-2 t\left(\alpha_{k} \pi_{R}^{k}+\beta_{k} \pi_{Y}^{k}\right)\right\}\right],
\end{gathered}
$$


where $\pi_{Y}^{k}=\pi_{T}^{k}+\pi_{C}^{k}$ and $\pi_{R}^{k}=\pi_{A}^{k}+\pi_{G}^{k}$. We can obtain the estimates of $f_{k}$,

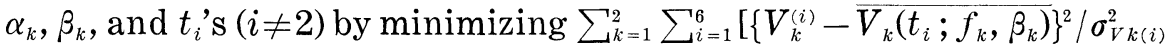
$\left.+\left\{S_{k}^{(i)}-S_{k}\left(t_{i} ; f_{k}, \alpha_{k}, \beta_{k}\right)\right\}^{2} / \sigma_{S k(i)}^{2}\right]$, where $V_{k}^{(i)}$ and $S_{k}^{(i)}$ are arithmetic averages of the difference data of species pairs of the $i$-th splitting (Table I).

The results are shown in Fig. 1. Our clock gives 19.1 \pm 3.6 , $15.9 \pm 2.9,4.9 \pm 1.0$, and $3.4 \pm 0.7 \mathrm{Myr}$ ( \pm refers to $1 \mathrm{SD}$ ) for the sepa-

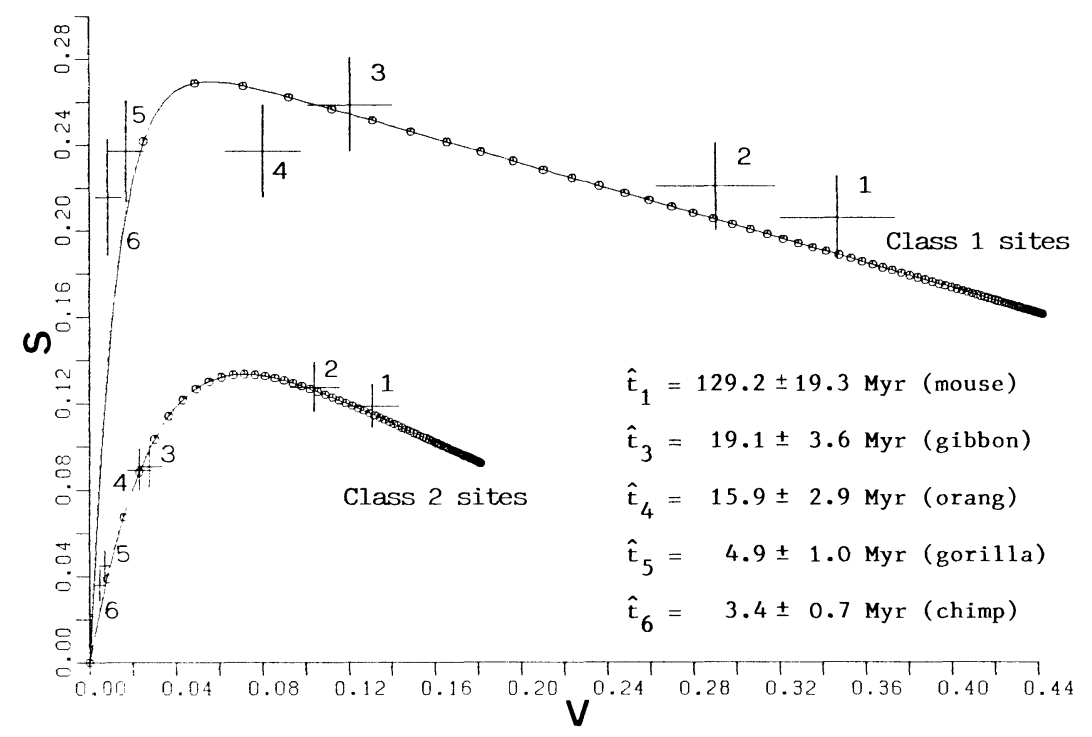

Fig. 1. Least squares fitting of the relation between $\mathrm{S}$ and $\mathrm{V}$. $\hat{f}_{1}=0.9288 \pm 0.0409, \quad \hat{\alpha}_{1}=0.3593 \pm 0.1181 \quad \mathrm{Myr}^{-1} \quad \hat{\beta}_{1}=0.0058 \pm 0.0009$ $\mathrm{Myr}^{-1}, \hat{f}_{2}=0.3795 \pm 0.0223, \hat{\alpha}_{2}=0.0502 \pm 0.0109 \mathrm{Myr}^{-1}, \hat{\beta}_{2}=0.0044 \pm$ $0.0007 \mathrm{Myr}^{-1}$. The figure that follows \pm is 1SD. Vertical and horizontal lines indicate 1SD of $\mathrm{S}^{(\mathrm{i})}$ and $\mathrm{V}^{(\mathrm{i})}$, respectively. The interval between neighbouring small circles along the curve indicates 5 Myr.

ration from human line of gibbon, orangutan, gorilla, and chimpanzee. They are in accord with the previous estimates for chimpanzee and gorilla. ${ }^{+1 . .1}$ Furthermore, they are compatible with the fossil evidence of orangutan and gibbon. The relative rate test ${ }^{3)}$ shows that our data indicates an approximate uniformity of the rate among bovine and primates. The mouse group, however, may have evolved more rapidly,,$^{13 \prime \prime}$ since $\hat{t}_{1}$ seems too large to be correct. It is known that mtDNA can pass across species boundary, ${ }^{1+)}$ and it is not impossible that such an event might have had happened among early hominoids. If it did occur, the times derived from our clock should reflect it. Sequence data of nuclear DNA, when it becomes available, should yield an evidence for or against such possibility. 
We thank Dr. H. Mizutani for comments. This work was supported by grants from the Ministry of Education, Science and Culture of Japan.

\section{References}

1) Kimura, M.: The Neutral Theory of Molecular Evolution. Cambridge Univ. Press, Cambridge (1983).

2) Dickerson, R. E.: J. molec. Evol., 1, 26-45 (1971).

3) Wilson, A. C. et al.: Ann. Rev. Biochem., 46, 573-639 (1977).

4) Sarich, V. M., and Wilson, A. C.: Science, 158, 1200-1203 (1967).

5) Andrews, P., and Cronin, J. E.: Nature, 297, 541-546 (1982).

6) Pilbeam, D.: ibid., 295, 232-234 (1982).

7) Raza, S. M. et al.: ibid., 306, 52-54 (1983).

8) Simons, E. L.: Phil. Trans. R. Soc. Lond., B 292, 21-41 (1981).

9) Brown, W. M. et al.: J. molec. Evol., 18, 225-239 (1982).

10) Anderson, S. et al.: J. molec. Biol., 156, 683-717 (1982).

11) Bibb, M. J. et al.: Cell, 26, 167-180 (1981).

12) Aquadro, C. F., and Greenberg, B. D.: Genetics, 103, 287-312 (1983).

13) Jacobs, L. L., and Pilbeam, D.: J. human Evol., 9, 551-555 (1980).

14) Ferris, S. D. et al.: Proc. natl. Acad. Sci. USA, 80, 2290-2294 (1983). 